\title{
Energy intake, growth rate and body composition of young Labrador Retrievers and Miniature Schnauzers fed different dietary levels of vitamin A
}

\author{
Thomas Brenten ${ }^{1 *}$, Penelope J. Morris ${ }^{2}$, Carina Salt ${ }^{2}$, Jens Raila ${ }^{3}$, Barbara Kohn ${ }^{4}$, \\ Leo Brunnberg ${ }^{4}$, Florian J. Schweigert ${ }^{3}$ and Jürgen Zentek $^{5}$ \\ ${ }^{1}$ Mars GmbH, Eitzer Straße 215, Verden 27283, Germany \\ ${ }^{2}$ WALTHAM ${ }^{\circledR}$ Centre for Pet Nutrition, Freeby Lane, Waltham on the Wolds, Melton Mowbray, Leicestershire, UK \\ ${ }^{3}$ Institute of Nutritional Science, University of Potsdam, Arthur-Scheunert-Allee 114-116, \\ Bergholz-Rebbrücke D-14558, Germany \\ ${ }^{4}$ Department of Veterinary Medicine, Clinic of Small Animals, Freie Universität Berlin, Oertzenweg 19b, \\ Berlin 14163, Germany \\ ${ }^{5}$ Department of Veterinary Medicine, Institute of Animal Nutrition, Freie Universität Berlin, Königin-Luise-Straße 49, \\ Berlin 14195, Germany \\ (Submitted 8 April 2013 - Final revision received 16 January 2014 - Accepted 3 February 2014 - First published online 25 March 2014)
}

\begin{abstract}
Research in rodents has shown that dietary vitamin A reduces body fat by enhancing fat mobilisation and energy utilisation; however, their effects in growing dogs remain unclear. In the present study, we evaluated the development of body weight and body composition and compared observed energy intake with predicted energy intake in forty-nine puppies from two breeds (twenty-four Labrador Retriever (LAB) and twenty-five Miniature Schnauzer (MS)). A total of four different diets with increasing vitamin A content between $5 \cdot 24$ and $104 \cdot 80 \mu \mathrm{mol}$ retinol (5000-100 $000 \mathrm{IU}$ vitamin A)/4184 kJ (1000 kcal) metabolisable energy were fed from the age of 8 weeks up to 52 (MS) and 78 weeks (LAB). The daily energy intake was recorded throughout the experimental period. The body condition score was evaluated weekly using a seven-category system, and food allowances were adjusted to maintain optimal body condition. Body composition was assessed at the age of 26 and 52 weeks for both breeds and at the age of 78 weeks for the LAB breed only using dual-energy X-ray absorptiometry. The growth curves of the dogs followed a breed-specific pattern. However, data on energy intake showed considerable variability between the two breeds as well as when compared with predicted energy intake. In conclusion, the data show that energy intakes of puppies particularly during early growth are highly variable; however, the growth pattern and body composition of the LAB and MS breeds are not affected by the intake of vitamin A at levels up to $104 \cdot 80 \mu \mathrm{mol}$ retinol $(100000 \mathrm{IU}$ vitamin $\mathrm{A}) / 4184 \mathrm{~kJ}(1000 \mathrm{kcal})$.
\end{abstract}

Key words: Dog growth: Vitamin A: Body composition: Energy intake

Adequate nutrition is a key factor for the optimal development of young dogs. Vitamin A is an essential nutrient for dogs; however, intake of dietary vitamin A can be variable and is dependent on the natural levels of vitamin A found in some raw materials used in petfood, especially liver. Previously, it has been shown that growing as well as adult dogs can tolerate a wide range of vitamin A levels in their diet ${ }^{(1-3)}$ due to their capacity to increase the levels of retinyl esters in serum ${ }^{(4)}$ and the ability to excrete vitamin $\mathrm{A}$ as both retinol and retinyl esters in the urine ${ }^{(3,5-7)}$. The impact of vitamin A and its metabolic product retinoic acid on energy metabolism in dogs is not clear, although data from rodents indicate an influence of retinoic acid on both thermogenesis and lipid synthesis via its actions when bound to the retinoic acid receptor $^{(7,8)}$. The main effect seems to be linked with the induction of uncoupling protein 1 (thermogenin) in brown adipose tissue. Mouse data show an increase in lipid oxidation in muscle tissue by retinoic $\operatorname{acid}^{(9)}$, and retinoids have been shown to induce uncoupling protein 3 in the muscle tissue of mice ${ }^{(10)}$.

Data on the safety of dietary vitamin A intake at levels up to $104.80 \mu \mathrm{mol}$ retinol (100 $000 \mathrm{IU}$ vitamin A)/4184 kJ (1000 kcal) have been reported previously with regard to the markers of vitamin A metabolism, haematological and biochemical variables and dual-energy X-ray absorptiometry ${ }^{(3)}$. In the present study, we evaluated the development of body

Abbreviations: LAB, Labrador Retriever; ME, metabolisable energy; MS, Miniature Schnauzer.

* Corresponding author: T. Brenten, fax + 494231 944964, email thomas.brenten@effem.com 
weight and body composition and compared observed energy intake with predicted energy intake in response to the potential impact of dietary vitamin A intake. Our hypothesis was that energy intake and accumulation of body fat in growing dogs would be unaffected due to the well-documented high tolerance to such levels of dietary vitamin A.

\section{Experimental methods}

The research protocol was evaluated and approved by the WALTHAM $^{\circledR}$ Internal Ethics Committee. The protocol has been described in detail previously ${ }^{(3)}$, and the experimental set-up is summarised briefly in the present study.

\section{Animals and housing}

The study was completed by forty-eight puppies from two different breeds, Labrador Retriever (LAB) and Miniature Schnauzer (MS). The puppies were group-housed with their mother until 8 weeks of age. Thereafter, they were housed in pairs in environmentally enriched kennels. The puppies had free access to an attached outdoor area, and participated daily in training and socialisation activities.

All puppies were neutered between week 36 and week 52.

\section{Clinical examination}

The puppies underwent physical examination before the start of the trial and every 4 weeks thereafter. Particular attention was paid to the signs of joint or muscle pain. In addition, any illness or injury between the examinations that required veterinary attention was considered as an adverse event. Adverse events were classified into ten categories: poor faecal quality; vomiting; foreign body ingestion; lameness; accident/ injury; skin conditions; eye conditions; ear conditions; dental conditions; urinary conditions. On each occasion, the type and duration of treatment were recorded.

\section{Diet and feeding}

The base diet used was a standard dry commercial recipe (Perfect Fit Junior; Mars GmbH) compliant with the 2008 FEDIAF (European Pet Food Industry Federation) recommendations $^{(11)}$ for growth and reproduction.

The predicted metabolisable energy (ME) of each batch of the diet was calculated according to the National Research Council $^{(12)}$, and the results of this calculation were multiplied by the factor $4 \cdot 184$ to convert kcal to $\mathrm{kJ}$. The calculated mean energy density of the diet was 16640 (SD 582) kJ/kg ( $n 10$ batches). Details about the nutrient composition and feeding regimen have been provided by Morris et $a l .{ }^{(3)}$. Briefly, the maternal bitch was fed the base diet throughout lactation until the puppies were fully weaned to the base diet at 6 weeks of age. Between weeks 8 and 26, the puppies were offered their daily ration in three meals and from week 27 until the end of the trial (week 52 for the MS breed and week 78 for the LAB breed) in two meals. Free access to drinking-water was given at all times.
The allocation of puppies to the diets with four different levels of vitamin A has been described by Morris et al. ${ }^{(3)}$. In brief, the diets contained the following levels of vitamin A per $4184 \mathrm{~kJ}$ (1000 kcal) ME: 5·24, 13·10, $78 \cdot 60$ and 104.80 $\mu \mathrm{mol}$ retinol (5000, 12 500, 75000 and $100000 \mathrm{IU}$ vitamin A)/4184 kJ (1000 kcal), respectively.

Although not fully validated in puppies, the body condition score was evaluated weekly using the WALTHAM ${ }^{\circledR}$ S.H.A.P.E. (Size, Health And Physical Evaluation) guide ${ }^{(13)}$, which is a seven-category system that uses visual and palpable characteristics to determine the amount of subcutaneous and abdominal fat. Each category is assigned an alphabetical character from A (underweight) to $G$ (obese), with D representing ideal where the outline of the ribs can be felt while applying light pressure when running the fingertips against the direction of the coat.

Feeding allowances were calculated from the amounts consumed during the previous week and adjusted weekly with the aim of maintaining the puppies on standard growth curves with ideal body condition scores ${ }^{(13,14)}$.

\section{Body composition}

The puppies of both breeds were scanned at 26 and 52 weeks of age, and the LAB puppies were also scanned at 78 weeks by means of dual-energy X-ray absorptiometry (total body software package, Lunar Hologic QDR-1000w; GE Healthcare). The puppies were fasted for at least $16 \mathrm{~h}$ and sedated with Torbugesic $(0.3 \mathrm{mg} / \mathrm{kg}$; Pfizer Animal Health), Medetomidine (MS breed: $20 \mathrm{mg} / \mathrm{kg}$, LAB breed: $5 \mathrm{mg} / \mathrm{kg}$; Pfizer Animal Health) and Midazolam (MS breed: $0.25 \mathrm{mg} / \mathrm{kg}$, LAB breed: $0 \cdot 20 \mathrm{mg} / \mathrm{kg}$; Roche Limited), and reversed with Atipamezole $(0.1 \mathrm{mg} / \mathrm{kg} ;$ Pfizer Animal Health). Estimates of lean body mass and fat mass were derived using the provided proprietary software package.

\section{Data analysis and statistics}

Data were analysed by means of a linear mixed model analysis including the fixed terms sample number (through time), sex, breed and dietary group, and also the baseline measurement of the variable was modelled. The model included the random terms dog and litter (taking account of possible similarities between littermates), with a correlation between successive samples (within an individual dog) accounted for by using an appropriate correlation structure (determined using graphical methods of residuals from a model with an identity correlation structure). Where necessary, data were log transformed to improve the distribution of the data, as assessed by residual plots. Non-significant terms were removed from the model.

Statistical analyses were performed using R2.10.1 (R Foundation for Statistical Computing) using the nlme package ${ }^{(15,16)}$

For the comparison of the energy intake of puppies in the trial with their predicted energy intake ${ }^{(12,17)}$, a linear mixed model was first fitted to the energy intake data with breed, week and breed $\times$ week interaction as fixed factors, litter and 
dog (nested in litter) as random factors, and an autoregressive ${ }^{(1)}$ correlation structure to take account of the correlation of successive measurements within a dog.

The expected energy intake based on the equation cited by the National Research Council ${ }^{(12,17)}$ was then calculated for each dog at each week of age, taking the adult weight of a dog to be the final weight recorded, which was the weight at week 52 for the MS puppies and at week 78 for the LAB puppies. The mean predicted ME requirement at each week was used to construct a predicted ME curve for each breed. This was then compared with the average actual intake by fitting a linear mixed model (with the same terms as that for the energy intake data) to the difference between the observed energy intake and the predicted energy intake to identify where the predictive equation and the observed energy intake significantly diverged.

For body composition, a linear mixed model was fitted to the data with the factors breed, sex, age, vitamin A group, litter and dog ID (nested in litter). However, as the MS puppies completed the study at an earlier time point, there were no data available for this breed at week 78 , which means that fitting breed and age as separate fixed factors with an interaction term in the conventional way was not possible. Therefore, a concatenated variable 'BreedAge' was created that has a level for each combination of breed and age (excluding week 78 for the MS puppies), which was used in the model. The effects of interest around breed and age (testing for breed effects, changes between the successive levels of age, and breed $\times$ age interaction effects) were tested using 'planned contrasts' that compared combinations of the levels of BreedAge.

Each body composition endpoint was initially analysed by a model containing all these terms, with litter and dog ID considered as random effects and the others as fixed effects. An autoregressive ${ }^{(1)}$ correlation structure was used to account for a possible correlation between subsequent time points within a dog. Error variance was initially allowed to differ between the two breeds. Non-significant fixed terms were then subsequently removed (one by one) until a model was reached where all the fixed effects were significant (the exception to this was BreedAge, which was left in the model in order to allow the planned contrasts to be tested). The 'breed-specific' nature of the error variance was also tested for significance and replaced with a single error variance estimate if possible. The resulting model was taken to be the final model. All endpoints were log-transformed before analysis, and means were exponentiated from the log scale to the original scale for display purposes and to ease interpretation.

All endpoints were separately subjected to Bonferroni correction to account for the presence of multiple endpoints; the overall significance level used was 0.05. Data are presented as means and (Bonferroni-adjusted) 95\% CI, unless otherwise stated, and $P$ values are reported as Bonferroni-adjusted values. The standard error of the mean is not reported as the non-linearity of $\log$ transformation (and its inverse) implies that only means and CI can be back-transformed.

\section{Results}

\section{Clinical examination}

Poor faecal quality was reported occasionally, with twenty individual puppies being affected. All cases were resolved within $3 \mathrm{~d}$. In the LAB breed, two cases of lameness without any apparent cause were observed; both cases were resolved following treatment in less than $7 \mathrm{~d}$.

\section{Growth}

All puppies maintained an ideal body condition score (score D) throughout the trial (data not shown). Body weight increased with time in a breed-specific manner ${ }^{(14)}$ (Fig. 1). Male MS puppies were heavier at $2 \cdot 1(\mathrm{SD} 0 \cdot 2) \mathrm{kg}$, compared with female MS puppies at $2 \cdot 0(\mathrm{SD} 0 \cdot 2) \mathrm{kg}$ at week 8 , which accounted for a difference of $7 \%$ between sexes. This difference increased to $16 \%$ at the end of the trial in week 52 . The final body weight during the observation period was 9.4 (SD 1.2) $\mathrm{kg}$ in male MS puppies and 7.9 (SD 1.0) $\mathrm{kg}$ in females. At week 8, the average body weight of the male LAB puppies was 4.5 (SD 0.4) kg and the average body weight of females was 4.4 (SD 0.3) kg, which suggested a $2 \%$ difference between sexes. At the end of the trial at week 78 , this difference increased to $10 \%$ with a final body weight of 28.9 (SD $3 \cdot 1) \mathrm{kg}$ in male LAB puppies and 25.9 (sD 1.6) $\mathrm{kg}$ in females.

There were no significant differences observed in body weight between the groups treated with different levels of dietary vitamin A at any time point (after accounting for sex and breed) as reported previously ${ }^{(3)}$.

\section{Intake of metabolisable energy}

There were no differences in energy intake per kg body weight or per $\mathrm{kg}$ metabolic body weight between the groups fed different levels of dietary vitamin $\mathrm{A}^{(3)}(P<0 \cdot 05)$. The mean energy allowance to maintain optimal body

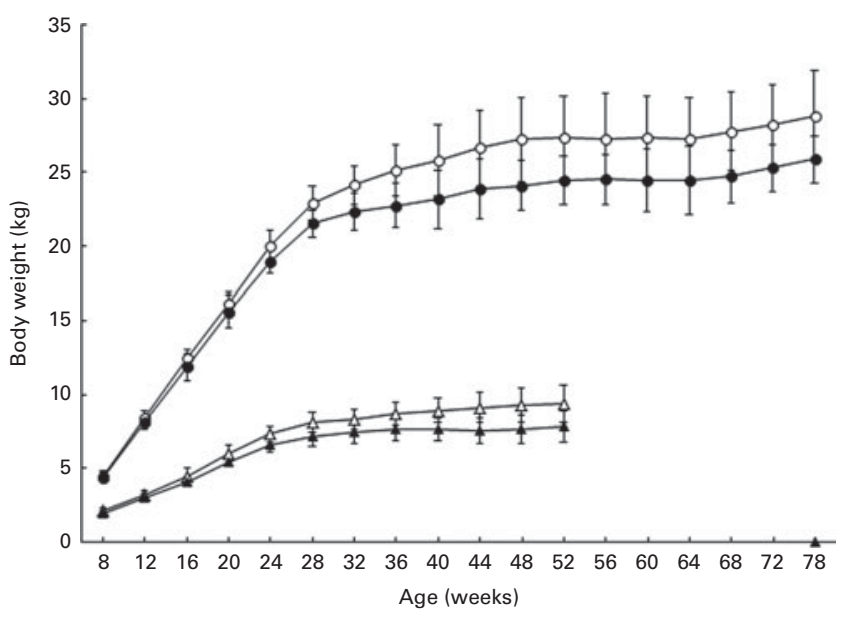

Fig. 1. Body-weight development by sex with age in Miniature Schnauzer (MS) and Labrador Retriever (LAB) puppies. Values are means, with standard deviations represented by vertical bars. O, Male LAB; $\bullet$, female LAB; $\triangle$, male MS; $\Delta$, female MS. 


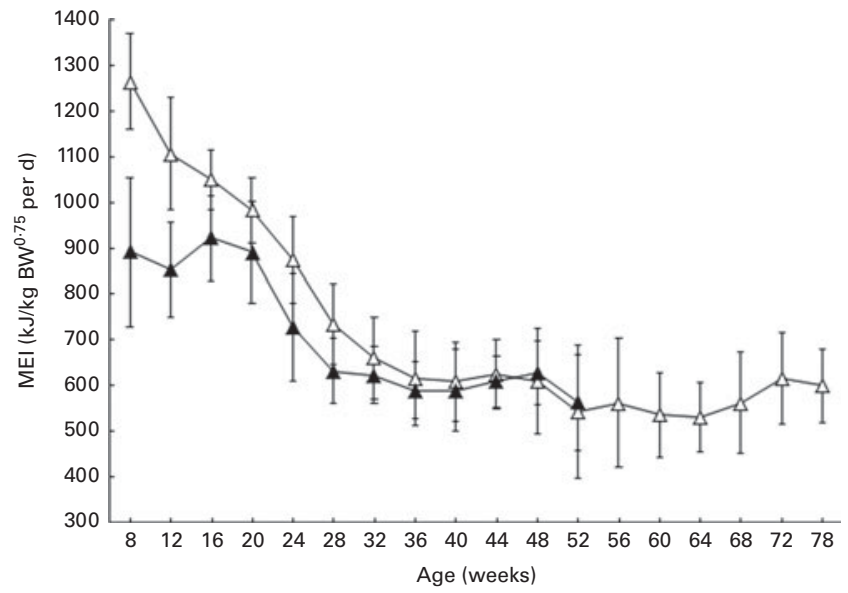

Fig. 2. Changes in metabolisable energy intake (MEI) with age in Miniature Schnauzer $(\Delta)$ and Labrador Retriever $(\boldsymbol{\Delta})$ puppies. Values are means, with standard deviations represented by vertical bars. BW, body weight.

condition was $890 \mathrm{~kJ} / \mathrm{kg}$ body weight ${ }^{0.75}$ per $\mathrm{d}$ in the MS puppies at the beginning of the study at week 8 , declining to $563 \mathrm{~kJ} / \mathrm{kg}$ body weight ${ }^{0.75}$ per $\mathrm{d}$ at week 52 . In the LAB puppies, the mean energy intake declined from 1263 to $599 \mathrm{~kJ} / \mathrm{kg}$ body weight ${ }^{0.75}$ per $\mathrm{d}$ at week 78 (Fig. 2).

The relative energy intake (based on $\mathrm{kJ} / \mathrm{kg}$ body weight per $\mathrm{d}$ ) in the MS puppies at $25 \%$ of the mature body weight was 1.58 times the maintenance energy requirement at week 52 . In the LAB puppies, it was 1.91 times the energy intake compared with week 78. This factor increased to 1.77 in the MS puppies and decreased to 1.65 in the LAB puppies at $50 \%$ of mature body weight. The factor decreased in both breeds to 1.33 and $1 \cdot 18$, respectively, at $80 \%$ of mature body weight. The energy intake of the LAB breed reached a mature energy requirement of $599 \mathrm{~kJ} / \mathrm{kg}$ body weight ${ }^{075}$ per d at $90 \%$ of mature body weight (Table 1 ).

The energy intake per kg metabolic body weight in the MS breed deviated from the calculated allowance as derived from the predictive equation ${ }^{(12,17)}$ from week 8 to 15 and week 18 to 23 inclusive. Until week 15, energy intake was significantly lower $(P<0.01)$ than the calculated allowance; between weeks 18 and 23 inclusive, energy intake was significantly higher $(P<0.05)$ than the calculated allowance (Fig. 3). The ME intake of the LAB breed was significantly lower $(P<0.01)$ than the calculated allowance only at week 9.
Between weeks 19 and 26 inclusive, energy intake was significantly higher $(P<0.05)$ than the predictions of the National Research Council (Fig. 4).

\section{Body composition}

There was no significant difference in the percentage of body fat between the two breeds of either sex at any of week 26, week 52 and week 78 (week 78 for the LAB puppies only) (Table 2). The planned contrasts for breed and the BreedAge interaction showed no significant effect between the breeds. Although the overall $P$ value for the combinations of the levels of BreedAge and sex showed a significant effect in our model $(P<0.01)$, post hoc testing was not able to determine which combination of breed, age and sex was relevant for the effect. This may be because the interaction term has a large number of levels and the post hoc procedure consequently involves a large number of pairwise comparisons; this means that the likelihood of false positives is much increased and the Tukey procedure is necessarily more conservative to account for this.

There was no significant difference in the percentage of lean body mass between the MS and LAB puppies at weeks 26 and 52. The percentage of lean body mass in the LAB puppies at week 78 was significantly higher than that in the MS puppies at week 26 (Table 3).

\section{Discussion}

The aim of the present study was to examine the possible effects of different dietary vitamin A concentrations on energy intake, growth rate and body composition during growth, using MS as a typical breed of small stature and LAB as a large breed. Energy intake was measured during the entire growth phase provided that energy allocation was adjusted to maintain optimal body condition. Body composition was assessed twice during the first year of life for both breeds and at 78 weeks of age for the LAB breed due to the prolonged growth phase. Because of the welldocumented high tolerance of dogs to vitamin A intakes at levels up to $104 \cdot 80 \mu \mathrm{mol}$ retinol (100000 IU vitamin A)/ $4184 \mathrm{~kJ}$ ( $1000 \mathrm{kcal})$, we hypothesised that there would be no effect at such levels of vitamin A on energy intake and body composition in growing dogs. This assumption was confirmed in principle by experimental data, even if questions on basic

Table 1. Energy intake (EI) by breed at different stages during growth relative to $\mathrm{El}$ at adulthood (Mean values and standard deviations)

\begin{tabular}{|c|c|c|c|c|c|c|c|c|c|c|c|c|c|}
\hline \multirow[b]{3}{*}{ Measures } & \multirow[b]{3}{*}{ Breed } & \multicolumn{12}{|c|}{ Percentage of mature BW } \\
\hline & & \multicolumn{2}{|c|}{$25 \%$} & \multicolumn{2}{|c|}{$35 \%$} & \multicolumn{2}{|c|}{$50 \%$} & \multicolumn{2}{|c|}{$80 \%$} & \multicolumn{2}{|c|}{$90 \%$} & \multirow{2}{*}{\multicolumn{2}{|c|}{$\begin{array}{c}\text { MEI }(\mathrm{kJ} / \mathrm{kg} \\
\left.\mathrm{BW}^{0.75}\right)\end{array}$}} \\
\hline & & Mean & SD & Mean & SD & Mean & SD & Mean & SD & Mean & SD & & \\
\hline El relative to maintenance & MS & 1.58 & 0.31 & 1.52 & 0.21 & 1.77 & 0.33 & 1.33 & 0.24 & $1 \cdot 13$ & 0.23 & 563 & 105 \\
\hline El (basis kJ/kg BW' ${ }^{0.75}$ ) & $\mathrm{LAB}$ & 1.91 & 0.33 & 1.85 & 0.30 & 1.65 & 0.24 & $1 \cdot 18$ & 0.18 & 1.00 & 0.21 & 599 & 81.5 \\
\hline
\end{tabular}

BW, body weight; MEI, maintenance energy intake; MS, Miniature Schnauzer; LAB, Labrador Retriever. 


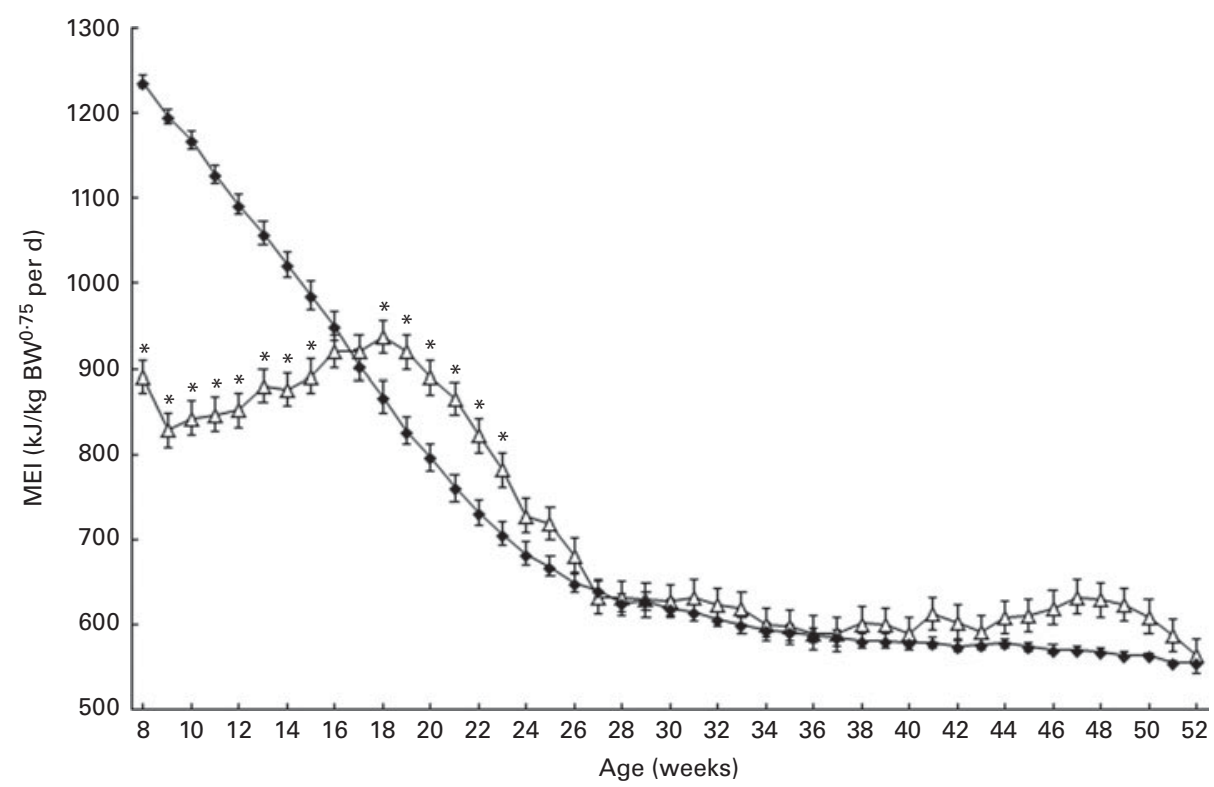

Fig. 3. Observed $(\Delta)$ and predicted $(\Lambda)$ metabolisable energy intakes (MEl; kJ/kg body weight $(B W)^{0.75}$ per d) in Miniature Schnauzer puppies from 8 to 52 weeks of age. Values are means, with their standard errors represented by vertical bars. * Mean values were significantly different between the observed and predicted MEI $(P<0.05)$ during weeks 8 to 15 and weeks 18 to 23 inclusive. It should be noted that the error bars for the observed energy intake naturally include some element of day-to-day variability while those for the predicted energy intakes do not.

mechanisms of the effects of vitamin A in dogs cannot yet be answered $^{(7-9)}$.

The growth rate of the LAB and MS puppies in the present study was comparable with the data from other studies ${ }^{(14,18-24)}$. Growth rate is significantly influenced by energy intake. Overfeeding with energy as well as severe under- or over supply of nutrients can predispose for developmental orthopaedic disorders, especially in large breeds ${ }^{(21,25-28)}$. Lifelong overfeeding has also been shown to have an impact on the occurrence of skeletal and other dysfunctions in adulthood and senescence ${ }^{(29)}$. Dietary energy has a key role in determining growth velocity and affects endocrine regulatory mechanisms. The increased biomechanical load seems to increase the risk of musculoskeletal disorders in young $\operatorname{dogs}{ }^{(30)}$, although epidemiological studies are not conclusive ${ }^{(28)}$. In addition to biomechanical effects, high energy intakes affect the endocrine system, such as insulin-like growth factor I and thyroid hormones, which in turn control local growth

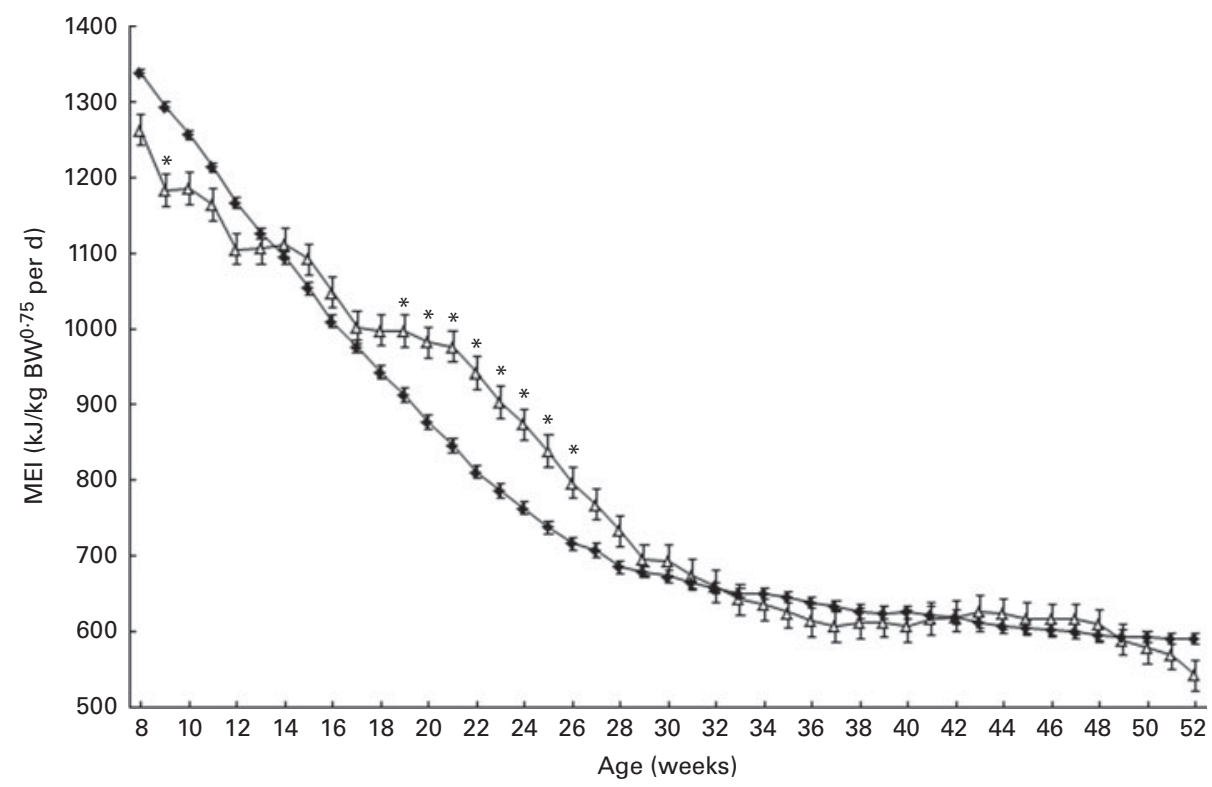

Fig. 4. Observed $(\Delta)$ and predicted $(\boldsymbol{\Lambda})$ metabolisable energy intakes (MEl; kJ/kg body weight $(B W)^{0.75}$ per d) in Labrador Retriever puppies from 8 to 52 weeks of age. Values are means, with their standard errors represented by vertical bars. * Mean values were significantly different between the observed and predicted MEI $(P<0.05)$ at week 9 and weeks 19 to 26 inclusive. It should be noted that the error bars for the observed energy intake naturally include some element of day-to-day variability while those for the predicted energy intake do not. 
Table 2. Change in total body fat (\%) with age in puppies*

(Mean values and $95 \%$ confidence intervals)

\begin{tabular}{|c|c|c|c|c|c|}
\hline Measures & Age (weeks) & Breed & Sex & Mean & $95 \% \mathrm{Cl}$ \\
\hline \multirow{10}{*}{$\begin{array}{l}\text { Percentage } \\
\text { of fat }\end{array}$} & \multirow[t]{4}{*}{26} & \multirow[t]{2}{*}{ MS } & $\mathrm{F}$ & $14 \cdot 3^{a}$ & $9.85,20 \cdot 9$ \\
\hline & & & $M$ & $14 \cdot 7^{\mathrm{a}}$ & $10 \cdot 1,21 \cdot 2$ \\
\hline & & \multirow[t]{2}{*}{ LAB } & $\mathrm{F}$ & $22 \cdot 1^{a}$ & $15 \cdot 1,32 \cdot 5$ \\
\hline & & & $M$ & $18 \cdot 7^{a}$ & $12 \cdot 9,27 \cdot 0$ \\
\hline & \multirow[t]{4}{*}{52} & \multirow[t]{2}{*}{ MS } & $\mathrm{F}$ & $12 \cdot 9^{a}$ & $8 \cdot 84,18 \cdot 8$ \\
\hline & & & $M$ & $16 \cdot 8^{a}$ & $11 \cdot 6,24 \cdot 3$ \\
\hline & & \multirow[t]{2}{*}{ LAB } & $\mathrm{F}$ & $19 \cdot 4^{a}$ & $13 \cdot 2,28 \cdot 4$ \\
\hline & & & $M$ & $21 \cdot 5^{\mathrm{a}}$ & $14 \cdot 9,31 \cdot 2$ \\
\hline & \multirow[t]{2}{*}{78} & \multirow[t]{2}{*}{ LAB } & $\mathrm{F}$ & $21 \cdot 4^{\mathrm{a}}$ & $14 \cdot 6,31 \cdot 4$ \\
\hline & & & $M$ & $22 \cdot 1^{\mathrm{a}}$ & $15 \cdot 3,32 \cdot 0$ \\
\hline
\end{tabular}

MS, Miniature Schnauzer; F, female; M, male; LAB, Labrador Retriever.

${ }^{a}$ No significant differences found in any of the pair-wise comparisons (Tukey).

* Data were analysed using a linear mixed model.

factors together with the proliferation of chondrocytes and the subsequent mineralisation of the newly formed tissue ${ }^{(31)}$. The definition of optimal growth rates for dogs is difficult and controversial; however, it should consider not only the expected typical shape of the breed, but also an optimal animal health status. Hence, an adequate energy supply is a key factor for the nutrition of young dogs, as has been shown in several studies with different breeds ${ }^{(21,22,25,32)}$. Data on energy intakes in specific breeds show considerable variability ${ }^{(12,33)}$, and there are only a few studies reporting energy intake, growth rate and body condition in the LAB breed ${ }^{(18-20,25,34,35)}$. Unlike the LAB breed, there are no data available for the energy needs of the MS breed in the growth period. Comparing the data collected in the present study with published values of other small breeds, there seems to be a relatively good agreement with the values obtained for beagles ${ }^{(6,16,22,36-41)}$. The MS breed reached $98 \%$ of the adult body weight at week 48 , which appeared in the expected range of $95-100 \%$ for this breed $^{(14,22)}$. The LAB breed reached $93 \%$ of the adult body weight, with an expected range of 88-95\%, respectively. However, body condition of the dogs has not been clearly defined in many studies. The assessment of body condition of growing dogs is more difficult compared with adult animals because a standardised system as for adult animals ${ }^{(13)}$ has not yet been developed and significant breed-specific influences such as pelvic circumferences ${ }^{(33)}$ exist. Visual assessment is complicated due to the observation that increased energy intake results in increased growth rate, but it is not necessarily leading to a visually detectable change in body conformation ${ }^{(37)}$. Therefore, body weight is not an accurate measure to assess body fat in growing dogs, and the relationship between the body condition score and body fat has been shown to be more accurate $^{(33)}$.

There was a good agreement between the observed energy intake in the LAB puppies and the expected values calculated by the predictive equation ${ }^{(12,17)}$ up to week 18 , but the equation showed an underestimation in energy requirement between weeks 19 and 26 inclusive. The energy intake of the MS puppies was significantly overestimated by the predictive equation $^{(12,17)}$ between weeks 8 and 15 , followed by a period of significant underestimation similar to the LAB puppies between weeks 18 and 23 inclusive. The reasons for such deviations might be breed-specific effects, housing conditions and the activity level of the dogs. In the present study, energy intake was the independent variable and feeding allowances were adjusted to maintain the puppies at an ideal body score. This approach may have led to a shift in growth rates with lower rates in the beginning followed by a compensatory phase.

The total amount of energy consumed until the end of week 52, however, remained for both breeds in a range of $\pm 2 \%$ compared with the total predicted energy intake.

Data from beagles and foxhounds have also shown considerable deviations between observed and mathematically derived energy intakes in young puppies of both breeds ${ }^{(37)}$ In the cited study, the dogs have been fed to achieve growth curves corresponding to theoretically expected agedependent weight development. This approach may have resulted in significant differences in energy allocation, because the growth capacity of young dogs is determined by individual factors. The dogs used in the present study were maintained under conditions that are to a certain extent similar to private households. The dogs were initially kept in groups and later in pairs, and were exercised according to age. It is often assumed that data from colony dogs differ from values for dogs in private housing. Besides the question of group housing $v$. individual housing with an anticipated higher activity level, it can be expected that many privately owned dogs have lower energy intakes due to the fact that the level of activity and 'intellectual challenge' is lower. However, variability in housing conditions is substantial. This could have an impact on energy expenditure ${ }^{(26)}$, although no data seem to be available for growing canines. The derived values for energy allowances can be used as guidelines for practical recommendations; however, but it is interesting to see that even in this highly standardised husbandry condition, data vary considerably between individuals. For a 12-month-old MS breed, the difference between the lower and upper CI for ME intake per $\mathrm{kg}$ metabolic body weight was $36.3 \mathrm{~kJ}( \pm 6 \%)$ and for the LAB breed, it was $39 \cdot 7 \mathrm{~kJ}( \pm 7 \%)$. Therefore, recommendations and nutritional guidelines should take this variability into account.

In addition to growth rate, body composition is an essential feature for the evaluation of growth curves and energy intake. In the present study, no significant differences were found

Table 3. Change in the percentage of lean body mass with age in puppies*

(Mean values and $95 \%$ confidence intervals)

\begin{tabular}{lcllc}
\hline Measures & Age (weeks) & Breed & Mean & $95 \% \mathrm{Cl}$ \\
\hline Percentage of & 26 & MS & $82 \cdot 9^{\mathrm{b}}$ & $78 \cdot 6,87 \cdot 5$ \\
$\quad$ lean body mass & & LAB & $77 \cdot 2^{\mathrm{a}, \mathrm{b}}$ & $72 \cdot 3,82 \cdot 3$ \\
& \multirow{2}{*}{52} & MS & $81 \cdot 5^{\mathrm{a}, \mathrm{b}}$ & $77 \cdot 3,86 \cdot 0$ \\
& \multirow{2}{*}{78} & LAB & $76 \cdot 3^{\mathrm{a}, \mathrm{b}}$ & $71 \cdot 6,81 \cdot 5$ \\
& & LAB & $75 \cdot 2^{\mathrm{a}}$ & $70 \cdot 5,80 \cdot 2$
\end{tabular}

MS, Miniature Schnauzer; LAB, Labrador Retriever.

${ }^{a, b}$ Mean values within a column with unlike superscript letters were significantly different (Tukey).

* Data were analysed using a linear mixed model. 
between the two breeds in the percentage of body fat. The observed data on the mean percentage of body fat in the LAB breed were $20 \cdot 4 \%$ at week $26,20 \cdot 5 \%$ at week 52 and $21.8 \%$ at week 78 , and were lower compared with other recent findings in growing $\mathrm{LAB}^{(42)}$

In the MS puppies, the mean percentage of body fat was $14.5 \%$ at week 26 and $14.9 \%$ at week 52 . The percentage of body fat for both MS and LAB puppies in the present study was within the range found previously in beagles and Foxhound-Boxer-Ingelheim Labradors ${ }^{(33)}$. The mean percentage of lean body mass in the LAB puppies at week 78 was $76 \cdot 3 \%$, which corresponds well to the data reported for adult Labrador Retriever from one previous study(34), where Labrador Retriever fed ad libitum had a mean percentage of lean body mass of $70 \%$ compared with $82 \%$ in the food-restricted group. This indicates an adequate energy allocation, which was made on the basis of body condition status.

The possible effects of increased vitamin A intake on growth intensity and body composition were of particular interest because there is some evidence in the literature of an effect of vitamin A and its metabolites on the energy balance of animals ${ }^{(9)}$. Based on available data on the growth curve as well as on body composition at the age of 26 and 52 weeks, no effect of increased vitamin A intakes was observed in the LAB and MS puppies. Thus, the conclusion seems justified that dogs raised on vitamin A levels up to $104.80 \mu \mathrm{mol}$ retinol (100000 IU vitamin A)/4184 kJ (1000 kcal) do not respond to a change in energy expenditure or utilisation. However, the underlying biochemical mechanisms are not clear. The high capacity to bind retinol in the form of retinyl esters in plasma might not result in the disruption of cellular retinoic acid homeostasis, which seems to have a major impact on energy metabolism in other species.

\section{Conclusion}

The present study shows that vitamin A levels up to $104 \cdot 80 \mu \mathrm{mol}$ retinol (100000 IU vitamin A)/4184kJ (1000 kcal) has no apparent effect on energy intake, growth rate or body composition in young dogs. These data confirm the high tolerance of this species to such levels of vitamin A. Data on energy intake, however, showed considerable variability between the two breeds, and also compared with the expected values using the predictive equation cited by the National Research Council, which requires further investigation.

\section{Acknowledgements}

The authors wish to recognise Karen Holmes, Gaelle Thomas and Amelia Wagstaff for their dedicated participation.

The present study was jointly funded by the FEDIAF and Mars Petcare. The FEDIAF had no role in the design, analysis or writing of this article. Mars Petcare contributed to the study design, conduct of the study, analysis of the data, interpretation of the findings and preparation of the manuscript.
All authors were involved in the design and oversight of the study. P. J. M. was responsible for the conduct of the study. C. S. performed the statistical analyses. T. B. and J. Z. wrote the paper. All authors were responsible for the final content of the manuscript.

T. B., P. J. M. and C. S. are employees of Mars Petcare. The rest of the authors have no conflicts of interest to declare.

\section{References}

1. Cho DY, Frey RA, Guffy MM, et al. (1975) Hypervitaminosis A in the dog. Am J Vet Res 36, 1597-1603.

2. Cline JL, Czarnecki-Maulden GL, Losonsky JM, et al. (1997) Effect of increasing dietary vitamin A on bone density in adult dogs. J Anim Sci 75, 2980-2985.

3. Morris PJ, Salt C, Raila J, et al. (2012) Safety evaluation of vitamin A in growing dogs. Br J Nutr 108, 1800-1809.

4. Schweigert FJ \& Bok V (2000) Vitamin A in blood plasma and urine of dogs is affected by the dietary level of vitamin A. Int J Vitam Nutr Res 70, 84-91.

5. Schweigert FJ, Thomann E \& Zucker H (1991) Vitamin A in the urine of carnivores. Int J Vitam Nutr Res 61, 110-113.

6. Worden AN, Bunyan J, Davies AW, et al. (1955) The urinary excretion of vitamin A by the dog. Biochem J 59, 527-528.

7. Zhao S, Li R, Li Y, et al. (2012) Roles of vitamin A status and retinoids in glucose and fatty acid metabolism. Biochem Cell Biol 90, 142-152.

8. Bonet ML, Ribot J \& Palou A (2012) Lipid metabolism in mammalian tissues and its control by retinoic acid (Special Issue: Retinoid and lipid metabolism). Biochim Biophys Acta 1821, 177-189.

9. Amengual J, Ribot J, Bonet ML, et al. (2008) Retinoic acid treatment increases lipid oxidation capacity in skeletal muscle of mice. Obesity (Silver Spring) 16, 585-591.

10. Felipe F, Bonet ML, Ribot J, et al. (2003) Up-regulation of muscle uncoupling protein 3 gene expression in mice following high fat diet, dietary vitamin A supplementation and acute retinoic acid-treatment. Int J Obes Relat Metab Disord 27, 60-69.

11. FEDIAF (2008) Nutritional Guidelines for Complete and Complimentary Pet Food for Cats and Dogs. Brussels: FEDIAF - European Pet Food Industry Federation.

12. National Research Council (2006) Nutrient Requirements of Dogs and Cats, 1st ed. Washington DC: National Academies Press.

13. German AJ, Holden SL, Moxham GL, et al. (2006) A simple, reliable tool for owners to assess the body condition of their dog or cat. J Nutr 136, 2031S-2033S

14. Hawthorne AJ, Booles D, Nugent PA, et al. (2004) Bodyweight changes during growth in puppies of different breeds. J Nutr 134, Suppl. 7, 2027S-2030S

15. Pinheiro J, Bates D \& DebRoy S, et al. (2010) nlme: linear and nonlinear mixed effects models. $\mathrm{R}$ package version 3.1-97. http://cran.r-project.org/web/packages/nlme

16. $\mathrm{R}$ Development Core Team (2009) $R$ : A Language and Environment for Statistical Computing. Vienna: R Foundation for Statistical Computing. http://www.R-project.org/

17. Blanchard G, Grandjean D \& Paragon BM (1998) Calculation of a dietary plan for puppies. J Anim Physiol Anim Nutr 80, 54-59.

18. Alexander JE \& Wood LL (1987) Growth studies in Labrador Retrievers fed a caloric-dense diet: time-restricted versus free-choice feeding. Comp Anim 14, 41-47. 
19. Booles D, Poore DW, Legrand-Defretin V, et al. (1994) Body composition of male and female Labrador retriever puppies at $20 \mathrm{wk}$ of age. J Nutr 124, Suppl. 12, 2624S-2625S.

20. Chakraborty PK, Stewart AP \& Seager SW (1983) Relationship of growth and serum growth hormone concentration in the prepubertal Labrador bitch. Lab Anim Sci 33, 51-55.

21. Hedhammar A, Wu FM, Krook L, et al. (1974) Overnutrition and skeletal disease. An experimental study in growing Great Dane dogs. Cornell Vet 64, Suppl. 5, 5-160.

22. Meyer H \& Zentek J (2010) Ernährung des Hundes (Nutrition of the Dog), 6th ed. Stuttgart: Enke Verlag.

23. Trangerud C, Grøndalen J, Indrebø A, et al. (2007) A longitudinal study on growth and growth variables in dogs of four large breeds raised in domestic environments. J Anim Sci $\mathbf{8 5}, 76-83$.

24. Huck JL, Biery DN, Lawler DF, et al. (2009) A longitudinal study of the influence of lifetime food restriction on development of osteoarthritis in the canine elbow. Vet Surg 38, 192-198.

25. Lust G, Geary JC \& Sheffy BE (1973) Development of hip dysplasia in dogs. Am J Vet Res 34, 87-91.

26. Meyer H \& Zentek J (1991) Energy requirements of growing Great Danes. J Nutr 121, Suppl. 11, 35-36.

27. Meyer H \& Zentek J (1992) Influence of various levels of energy intake on development of body weight and skeleton in growing Great Danes. 1. Growth rate and energy requirement. J Vet Med A 39, 130-141.

28. Krontveit RI, Nodtvedt A, Saevik BK, et al. (2010) A prospective study on canine hip dysplasia and growth in a cohort of four large breeds in Norway (1998-2001). Prev Vet Med $\mathbf{9 7}$, 252-263.

29. Lawler DF, Larson BT, Ballam JM, et al. (2008) Diet restriction and ageing in the dog: major observations over two decades. Br J Nutr 99, 793-805.

30. Dämmrich K (1991) Relationship between nutrition and bone growth in large and giant dogs. J Nutr 121, Suppl. 11, S114-S121.

31. Blum JW, Zentek J \& Meyer H (1992) Investigations on the influence of different energy supply on growth performance and skeletal development of growing Great Danes. 2. Effects on the insulin-like growth factor I and on thyroid hormones. J Vet Med A Physiol Pathol Clin Med 39, 568-574.

32. Kealy RD, Olsson SE, Monti KL, et al. (1992) Effects of limited food consumption on the incidence of hip dysplasia in growing dogs. J Am Vet Med Assoc 201, 857-863.

33. Dobenecker B (2008) Comparison of body weight, body condition score, and pelvic circumference in dogs to predict adipose tissue as measured by DEXA. In Proceedings ESVCN Conference, 25-27 September 2008, Vienna, Austria.

34. Kealy RD, Lawler DF, Ballam JM, et al. (2002) Effects of diet restriction on life span and age-related changes in dogs. $J \mathrm{Am}$ Vet Med Assoc 220, 1315-1320.

35. Kienzle E \& Rainbird A (1991) Maintenance energy requirement of dogs: what is the correct value for the calculation of metabolic body weight in dogs? J Nutr 121, Suppl. 11, S39-S40.

36. Allard RL, Douglass GM \& Kerr WW (1988) The effects of breed and sex on dog growth. Comp Anim Pract 2, 15-19.

37. Dobenecker B, Endres V \& Kienzle E (2011) Energy requirements of puppies of two different breeds for ideal growth from weaning to 28 weeks of age. J Anim Physiol Anim Nutr (Berl) 97, 190-196.

38. Höfling B (1989) Untersuchungen über die Aufzuchtintensität von Junghunden unter besonderer Berücksichtigung der Skelettentwicklung (Studies on the breeding intensity of young dogs with particular emphasis on skeletal development). PhD Thesis, Tierärztliche Hochschule Hannover, Germany.

39. Romsos DR, Belo PS, Bennink MR, et al. (1976) Effects of dietary carbohydrate, fat and protein on growth, body composition and blood metabolite levels in the dog. $J$ Nutr 106, 1452-1464.

40. Sheng HP \& Huggins RA (1971) Growth of the beagle: changes in chemical composition. Growth 35, 369-376.

41. Teute HW \& Lenz R (1976) Eignungsprüfung verschiedener Futterarten für die Zucht und Aufzucht von Beagle-Hunden (Aptitude test different types of feed for breeding and rearing of beagle dogs). Arzneimittelforschung 26, 1875-1884.

42. Schoenherr WD, Macleay JM \& Yamka RM (2010) Evaluation of body composition and cartilage biomarkers in large-breed dogs fed two foods designed for growth. Am J Vet Res $\mathbf{7 1}$ 934-939. 